\title{
EXCLUSÃO COMO RUPTURA DE LAÇOS SOCIAIS: UMA CRÍTICA DO CONCEITO
}

\section{Giuliana Franco Leal ${ }^{1}$}

\begin{abstract}
Resumo
Neste artigo, abordamos teoricamente o conceito de exclusão social como fragilização e ruptura de laços sociais, especialmente na bibliografia francesa (na qual se encontram suas origens) e brasileira. Investigamos a pertinência do conceito para caracterizar o fenômeno ao qual se refere, seus alcances e limites.
\end{abstract}

Palavras-chave: Exclusão social. Desigualdade social. Classes sociais.

\section{Exclusion as the Severing of Social Ties: A Conceptual Criticism}

\begin{abstract}
In this article, we deal theoretically with the concept of social exclusion as the weakening and rupture of social ties, especially in the French and Brazilian literatures. We investigate the pertinence of the concept for characterizing the phenomenon it refers to, its scope and its limits.
\end{abstract}

Keywords: Social exclusion. Social inequality. Social classes.

${ }^{1}$ Doutora em Sociologia pela Unicamp e professora na Academia da Força Aérea. 


\section{INTRODUÇÃO}

0

termo "exclusão social" não é novo no vocabulário das ciências sociais nem do senso comum. Mas passou a ser empregado mais freqüentemente desde a década de 1990. Não é a toa que certas noções passam a ser mais usadas em momentos determinados. Sua recorrência expressa o destaque de algum problema social que traz incômodo. Assim, estudar uma noção que emerge num dado momento e numa certa sociedade significa trazer à luz problemas e questões que se encontram então em evidência.

Além disso, quando um conceito é construído pelas ciências sociais, ele não está isolado. Pelo contrário, está cercado, norteado e/ou embasado por uma série de outras noções e conceitos, hipóteses, teses e pressuspostos teórico-metodológicos. Enfim, esse conceito faz parte de uma perspectiva teórico-metodológica que se encontra também em evidência.

Torna-se ainda mais importante entender um conceito com certa projeção quando percebemos que a forma como ele é usado tem implicações sobre as possibilidades de pensar a resolução prática do problema social ao qual se refere.

Por todas essas razões, estudamos o conceito de exclusão social ${ }^{2}$. Como as definições são várias, não seria possível inicialmente um exame aprofundado de todas elas. Assim, escolhemos uma das definições mais presentes na literatura: aquela segundo a qual a exclusão social significa o enfraquecimento ou a ruptura dos laços sociais que ligam o indivíduo à sociedade e/ou a condição a que ele chega após tal ruptura.

Em meio a toda a diversidade de definições da exclusão social ${ }^{3}$, o conceito que faz referência aos vínculos sociais é interessante por três motivos principais. Primeiramente, por ser construído teoricamente, de modo bem pensado por vários autores, relacionado a um conjunto de outros conceitos e pressupostos teóricometodológicos. Em segundo lugar, esse conceito é bastante discutido mesmo pelos autores que pensam a exclusão social de modo diferente, de modo que pode ser tomado como eixo de um diálogo, para traçar o panorama do debate sobre o tema.

\footnotetext{
${ }^{2}$ Segundo Minayo (1993), conceitos são unidades de significação necessários à definição da forma e do conteúdo de uma teoria. Já as "imagens" usadas para explicar a realidade, sem necessariamente muita clareza, podem ser chamadas de noções.

${ }^{3}$ Outras definições referem-se à inserção subordinada nas relações de trabalho e de poder, aos impedimentos à realização de direitos, bem como a formas específicas de exclusão (em relação ao mercado de trabalho, ao consumo, à educação etc.).
} 
Por fim, essa definição abre portas para que se discutam mais diretamente as novidades em relação ao contexto social anterior e a outras abordagens e conceitos.

No próximo item, apresentaremos a origem e a evolução do conceito. Em seguida, discutiremos a perspectiva da qual o conceito faz parte, suas principais preocupações e questões.

Ao longo dessa análise, procuraremos os elementos necessários para responder às seguintes questões: o conceito de exclusão social tal como definido acima é pertinente para pensar o problema ao qual se refere? Quais suas fragilidades? E seus pontos fortes? Enfim, quais seus limites e alcances?

\section{A FORMAÇÃ̃o DO CONCEITO}

A conceituação da exclusão como ruptura e fragilização de vínculos sociais começou a se desenvolver na França, como atesta Silver (1994) em artigo dedicado a mapear o debate internacional sobe o tema. Alguns eventos formam o contexto propício à busca de novos conceitos que dêem conta dos problemas que assustam a Europa, a partir da década de 1970. São eles: 0 aumento do desemprego aberto, a precarização dos postos de trabalho (atestada pela proliferação de contratos em tempo parcial e por tempo determinado, bem como por modalidades informais de trabalho), a chamada "nova pobreza", que aumenta atingindo setores da população antes estáveis, e as dificuldades do Estado em manter os antigos padrões de proteção social, assentados centralmente sobre o trabalho assalariado. Na sociedade francesa, especialmente a integração dos imigrantes, que compõem grande parte das vítimas dos processos de desestabilização do mundo do trabalho, é uma questão que coloca de modo privilegiado o problema da exclusão social.

No Brasil, a discussão sobre ruptura de vínculos freqüentemente abriga um diálogo forte com a literatura francesa. Reconhece, entretanto, peculiaridades de nossa sociedade economicamente periférica. Embora aqui o desemprego aberto aumente desde o início da década de $1980^{4}$, a informalidade, as condições precárias de trabalho e a pobreza são problemas há muito conhecidos. Tamanho é seu enraizamento na sociedade brasileira que se pode falar até mesmo num princípio excludente (NASCIMENTO, 1994a), gerado pelo mercado de trabalho deficiente na geração de empregos estáveis, pelas relações de exploração extremadas,

\footnotetext{
${ }^{4}$ A taxa total de desemprego vai de 3,8\% a 9,9\% de 1981 a 2001, segundo Rocha (2005), a partir de microdados da PNAD/IBGE.
} 
pela pobreza passada de geração a geração, pela discriminação histórica a certos segmentos da população (mulheres, negros, índios) e pelos percalços na construção de uma cidadania plena extensiva ao conjunto dos brasileiros. Esses seriam elementos de uma "velha exclusão" - usando um termo de Pochmann e Amorim (2003) - que se mescla a uma "nova exclusão".

As novas facetas da exclusão consistem em modalidades recentemente surgidas de desemprego e subemprego ${ }^{5}$, no aumento das taxas de desemprego aberto, nas novas crises do Estado naquilo que se refere à proteção social (basta ver a discussão sobre a crise da Previdência, no Brasil), no aumento da violência urbana e da insegurança que provoca. Por fim, também pode ser mencionada como parte dessas novidades a discussão sobre o processo subjetivo de individualização ocorrido nas sociedades contemporâneas e, nesse bojo, sobre a transformação das famílias, com redução de seu tamanho, e das relações comunitárias e de vizinhança nas grandes cidades, com diminuição das relações de sociabilidade primária. Frente às transformações, o conceito de exclusão social faz parte de uma tentativa de responder a questões novas.

É verdade que nem sempre a idéia de quebra de laços aparece sob o nome de "exclusão social". Alguns autores importantes e recorrentemente citado pela bibliografia que se ocupa do tema usam outros termos, tais como "desfiliação" (CASTEL, 1995), "desqualificação social" (PAUGAM, 1991) ou "desinserção social” (GAULEJAC e TABOADA-LÉONETTI, 1994). Encontramos ainda algumas semelhanças com a exclusão social no conceito de "apartação", de Cristóvam Buarque (1999).

\section{O CONCEITO DE EXCLUSÃO SOCIAL E OS LAÇOS SOCIAIS}

Vimos que o conceito de exclusão social diz respeito à fragilização e ruptura de laços sociais. Que laços são esses? São aqueles que, nas sociedades capitalistas contemporâneas, exercem algum poder de integração dos indivíduos a elas.

0 mais destacado pela bibliografia é o laço do trabalho assalariado. A idéia por trás dessa ênfase está na tese, bem explicitada por Barel (1990), de que

\footnotetext{
${ }^{5}$ Segundo Pochmann (2005), a taxa de desemprego para pessoas com mais de oito anos de escolaridade aumentou de 22,2\% para 45,3\%, de 1989 para 1998; entre as ocupações que mais perderam postos de trabalho nos anos 90 , no Brasil, estão as de chefes intermediários administrativos e engenheiros. Além disso, a década de 1990 é marcada por novas modalidades de contratos de trabalhos com menos direitos e garantias, tais como a subcontratação e a tercerização.
} 
o trabalho, desde os primórdios da sociedade capitalista, tem sido um importante fator de integração dos indivíduos à sociedade, por fornecer recursos para a reprodução da vida, um lugar na estrutura social e balizas para a organização espaço-temporal, não apenas dos indivíduos como também da organização social. Nesse sentido, o trabalho assalariado vinha exercendo o papel do "grande integrador", que tem como funções essenciais a organização, a manutenção da ordem e a criação do sentido (em todos os casos, individual ou social).

Por todas essas funções preenchidas pelo trabalho para a reprodução da vida social, as sociedades capitalistas teriam vivido nos últimos séculos uma "civilização do trabalho", ou seja, uma "ordem humana na qual toda a sociedade e todos os seus componentes começam a se articular ou a se rearticular em torno do trabalho" (BAREL, 1990, p.91).

0 problema que vivemos desde a década de 1970, aproximadamente, é que o trabalho assalariado já não consegue preencher maciçamente as funções que se passou a esperar dele. Castel (1995) é quem melhor explana sobre essa crise da sociedade assalariada na França. Em As metamorfoses da questão social, ele mostra que a sociedade salarial se fortaleceu a partir de meados do século XX, chegou ao seu ápice na década de 1970 e, desde então, experimentou uma degradação.

Sociedade salarial, para Castel, é aquela em que o trabalho assalariado é generalizado (em 1975, 82\% da população francesa era assalariada), a identidade social dos indivíduos é definida a partir da posição ocupada na condição salarial e as formas de seguridade e proteção social têm seu suporte na cotização dos recursos provenientes do trabalho, com mediação do Estado de Bem-Estar Social, em seu estágio mais desenvolvido.

A degradação da sociedade salarial vem com o aumento do desemprego e a precarização do trabalho, pois milhares de pessoas perdem a identidade conferida pelo trabalho e o sistema de solidariedade e proteção anterior entra em crise. Nesse cenário, crescem a incerteza e a insegurança das pessoas face ao presente e ao futuro, e confere-se o estigma da inutilidade social àqueles que não encontram trabalho remunerado. Essas pessoas estão mal-integradas na sociedade, ou nas palavras de Castel, "em processo de desfiliação", sob o forte risco de não encontrar mais nela um lugar social reconhecido.

Paugam (1991), mais centrado sob a trajetória vivida pelos indivíduos, enfatiza, a partir de pesquisa empírica qualitativa, que a ausência de trabalho 
estável muito freqüentemente provoca nos indivíduos - a despeito dos modos diferenciados que cada pessoa constrói para lidar com o problema - um sentimento de falta de sentido e de perda do estatuto. Assim, é recorrente que os desempregados de longa duração, por vergonha e apatia, rareiem o contato com a família e os amigos. Também vários problemas de saúde são mais freqüentes entre os desempregados.

Clavel (1998), também estudioso da exclusão social, menciona ainda que a ausência do trabalho pode conduzir à perda do sentimento de pertencimento $\mathrm{a}$ um grupo, a uma classe, a um sindicato, a uma cultura. Enfim, o trabalho faz falta porque era parte da construção de uma identidade coletiva e pessoal.

No caso brasileiro, não se pode falar propriamente numa crise da sociedade salarial, nos moldes delineados por Castel (1995). De acordo com Kowarick (2002), essa modalidade societária, na acepção forte do termo, nunca existiu no Brasil nem nos demais países da América Latina, uma vez que

ela supõe não apenas uma força de trabalho majoritariamente empregada de maneira permanente e regular quanto à legislação vigente, mas também percursos profissionais protegidos por contratos coletivos que levem à ascensão social e econômica ou, pelo menos, garantam certos direitos aos que nessa trajetória forem alijados do mercado de trabalho (...). Aqui as garantias do (não) trabalhador sempre foram restritas e frágeis. 0 mínimo que se pode dizer é que no Brasil jamais houve instituições políticas, sindicais ou comunitárias com força suficiente para garantir a efetivação de direitos básicos do mundo do trabalho ou proteger das intempéries do mundo urbano o morador, transeunte e usuários de serviços básicos (KOWARICK, 2002, p.16).

Contudo, Kowarick (2002) considera pertinente falar em "desenraizamento do assalariamento formal" para aquela fatia da população que se torna desempregada ou sem contrato formal de trabalho, somada a toda a população caracterizada pela intermitência e precariedade do trabalho. Nesse sentido,

houve perdas [no Brasil] não tanto nas práticas de lutas do mundo fabril e sindical, mas nas experiências de regularidade quanto aos procedimentos provenientes de trabalho contínuo, assalariado ou autônomo e, para boa parcela, à segurança conferida pela previsibilidade da aposentadoria por tempo de serviço. Nesse sentido, penso ser possível afirmar que está ocorrendo um vasto processo de desenraizamento do mundo do trabalho, na medida em que para muitos ele se tornou informal, instável e aleatório (KOWARICK, 2002, p.21). 
Nas abordagens que associam a exclusão social ao corte de vínculos sociais, o consumo é geralmente pensado como uma conseqüência do trabalho. É claro que, numa sociedade capitalista, é pouco provável que alguém sobreviva sem participar minimamente do mercado de consumo, ainda que de forma precária e intermitente. Assim, a exclusão dessa dimensão diz respeito apenas a certo padrão de consumo, definido normativamente por cada sociedade como o mínimo digno e/ou necessário.

Enfatizada, sobretudo, como decorrência do corte do laço com o mundo do trabalho, a perda do vínculo com a sociedade por meio do consumo parece-nos muitas vezes sobrevalorizada pela bibliografia que se apóia no tema da exclusão social como desintegração. Pode-se questionar se o trabalho é sempre necessário e diretamente um fator de integração social acima do consumo. No caso das donasde-casa, por exemplo, não há trabalho assalariado e nem por isso elas estão menos integradas. Como Gaulejac (1994) percebeu por meio de entrevistas qualitativas, 0 pertencimento de classe dessas mulheres identifica-se com o do marido. Da mesma forma, não se poderia afirmar que uma pessoa que viva de rendas tenha, em função disso, déficits de integração social. Esses casos ajudam a levantar a hipótese de que o consumo possa ser mais decisivo que o trabalho remunerado para evitar a exclusão.

Consideramos, como Bauman (1998), que os hábitos de consumo tecem laços simbólicos, participando da criação de uma identidade entre indivíduos que têm em comum o mesmo padrão de consumo de bens materiais e simbólicos. Os que estão fora de um padrão de consumo médio são tratados como "um 'problema', como a 'sujeira' que precisa ser removida, (...) objetos fora de lugar" (BAUMAN, 1998, p.24).

Igualmente, o pertencimento a grupos sociais com interesses comuns, tais como partidos políticos e movimentos sociais, pode ser fonte de identidade. Fretigné (1999), expondo as várias vias de exclusão, também ressalta a ausência de participação nas instituições do "mundo cívico" (organizações políticas, partidos, sindicatos), que anula os poderes de representação. Também o enfraquecimento das instituições como criadoras e zeladoras de valores compartilhados - por exemplo, escolas e igrejas - são um importante fator de exclusão, apontado em especial por Paugam (1994).

Os laços de sociabilidade primária ganham uma ênfase maior da bibliografia. Castel (1995) considera serem estes laços que constituem o segundo 
eixo de integração mais importante, juntamente com o trabalho. Desse modo, o enfraquecimento dos laços familiares e comunitários estaria na base do individualismo contemporâneo, que torna as pessoas menos protegidas e, assim, mais vulneráveis à desfiliação. Gaulejac e Taboada-Leonétti (1994) também destacam a efemeridade dos laços comunitários como caminho fácil para 0 isolamento social.

Todavia, esse tema é imensamente controverso. Ferreol (1992) afirma que as transformações nas formas de organização familiar ocorridas nas últimas décadas (mais gente morando sozinha, menos filhos por família, aumento das taxas de divórcio etc.) não significam que foram diminuídas a importância e a intensidade das relações familiares.

No caso brasileiro, Escorel (1999), pesquisadora da exclusão social por vias teóricas e empíricas, considera que a perda dos laços familiares é mais importante que a dos vínculos dados pelo trabalho. No Brasil, a família tem sido historicamente um grande fator de identidade, tendo papel determinante na definição do lugar social dos indivíduos, além de ser uma fonte essencial de proteção nos momentos de instabilidade no trabalho, aqui bastante comuns.

Além desses laços de trabalho, consumo, pertencimento institucional e sociabilidade primária enfatizados pela bibliografia nacional e internacional, há um laço peculiar enfatizado por pesquisadores brasileiros: o vínculo dado pelo reconhecimento do outro como um semelhante, pela sua humanidade.

Nascimento (1994) e Oliveira (1997) defendem que o desemprego de longa duração, sem perspectivas de reinserção, atribui aos "excluídos" uma pecha de inutilidade. Num cenário urbano de insegurança crescente frente à violência, 0 imaginário popular pode associar pobreza e violência. Assim, populações pobres e desempregadas tendem a ser vistas como potencialmente ameaçadoras. Por isso, tornam-se, elas mesmas, ameaçados de extermínio. Nesse caso, o que acontece é 0 não reconhecimento do direito a ter direitos para certos grupos.

É um cenário semelhante ao que expõe Cristovam Buarque (1999), ao cunhar o conceito de apartação, para falar de uma situação de segregação gerada pela desigualdade socioeconômica extrema. Tratar-se-ia da atribuição, pelos integrados em relação aos apartados, de uma dessemelhança, o não reconhecimento de uma identidade comum de seres humanos com os mesmos direitos básicos. Estariam rompidos, assim, laços de solidariedade e pertencimento à própria humanidade. 
Os diversos vínculos de pertencimento do indivíduo à sociedade estão, na verdade, interligados. 0 fracasso em uma esfera aumenta as chances de fracasso em outras, como mostram as pesquisas empíricas de Paugam (1991), na França, e de Escorel (1999), no Brasil. Como esclarece Xiberras (1994), em livro que analisa vários estudos sobre o tema, as várias formas de exclusão (do mercado de trabalho, do mercado de consumo, do padrão normativo da sociedade etc.) não implicam, separadamente, num isolamento do indivíduo. Mas a somatória delas coloca 0 indivíduo em processo de exclusão social.

Sob essa perspectiva, a exclusão social é, como resume Escorel, um processo porque fala de um movimento que exclui, de trajetórias ao longo de um eixo inserção/exclusão, e que é potencialmente excludente (vetores de exclusão ou vulnerabilidades). Mas é, ao mesmo tempo, um estado, a condição de exclusão, o resultado objetivo de um movimento (ESCOREL, 1999, p.67).

Significando a ausência ou a fragilidade extrema de vínculos do indivíduo com a sociedade, a exclusão social representa uma espécie de "morte social":

a exclusão social se caracteriza não só pela extrema privação material mas, principalmente, porque essa mesma privação material 'desqualifica' seu portador, no sentido de que the retira a qualidade de cidadão, de brasileiro (nacional), de sujeito e de ser humano, de portador de desejos, vontades e interesses legítimos que o identificam e diferenciam. A exclusão social significa, então, o não encontrar nenhum lugar social, o não pertencimento a nenhum topos social, uma existência limitada à sobrevivência singular e diária (ESCOREL, 1999, p.81).

É claro que não se pode imaginar uma pessoa que viva próxima às demais sem nenhum tipo de contato com a sociedade. Viver entre os outros exige e implica, pelo menos, num mínimo de aceitação das normas e valores comuns. Além disso, não se pode sobreviver sem tipo nenhum de consumo, e consumir exige 0 estabelecimento de relações sociais, nem que seja pela mendicância. Assim, parece falho o conceito de exclusão como condição. Ele faz mais sentido como processo de vulnerabilizações múltiplas.

É interessante perceber que quando a exclusão é pensada como processo, os cortes de laços são pensados como características do fenômeno. Quando pensada como condição, tais cortes são interpretados como causas dele. Contudo, dizer que a causa da exclusão está, por exemplo, no desemprego, não explica como ele se 
constituiu, quais suas raízes e suas razões. Desse modo, o conceito de exclusão social presta-se mais a uma descrição do que a uma análise propriamente dita.

Além disso, o corte de vínculos, ao dizer respeito à relação do indivíduo (pobre, desempregado, com relações de sociabilidade pouco sólidas) com a sociedade capitalista, dirige àquele o seu foco. Nesse sentido, a exclusão social é a contrapartida, no âmbito individual, da desintegração que ocorre no âmbito macro-social.

Desse modo, é dentro de uma perspectiva que tem como questão central a integração social que a discussão sobre os cortes de laços sociais se situa. Como veremos no próximo item, tal abordagem tem suas implicações.

\section{A EXCLUSÃo SOB A PERSPECTIVA DA INTEGRAÇÃO SOCIAL}

Mesmo quando não explicitamente conceituada, a noção de integração perpassa as discussões sobre a exclusão social quando elas se fazem em termos de laços sociais. A idéia de solidariedade, formada pelos laços de interdependência e pela existência de valores comuns, dá um tom durkheimiano ao debate.

Em geral, a idéia de integração presente na bibliografia analisada refere-se à fragilidade de grupos de referência para os indivíduos, ao enfraquecimento das instituições nacionais, à fluidez dos valores e das normas sociais, às dificuldades do Estado em manter formas eficientes de proteção social e à crise do trabalho assalariado como âncora de pertencimento social para o conjunto da população. A temática é a da crise de uma sociedade que se transforma, não se sabe bem em que direção.

Ainda que o conceito de integração admita a existência de conflitualidade, é na solidariedade e no pertencimento que ele se centra. Nessa perspectiva, a contradição é deixada de lado, junto com conceitos como luta de classes e exploração.

Essa tendência a substituir o conceito de exploração pelo de exclusão é percebida de forma geral na literatura sobre a quebra de laços sociais. Em Touraine (2005), vemos um representante explícito dessa tendência. Tendo como tese central de sua obra recente a passagem da sociedade industrial para a pósindustrial, ele considera a exclusão - no mesmo sentido que temos visto - como uma categoria-chave da sociedade contemporânea. 
Segundo o autor, estaríamos passando por mudanças que refletem a importância crescente da informação, a localização dos conflitos mais na esfera do consumo do que na produção, o declínio das categorias sociais (sobretudo a de classes sociais) do centro das principais questões da sociedade e a dissolução de mecanismos de pertencimento a grupos e instituições sociais integradoras. Nas palavras de Touraine:

(...) não estamos mais em uma pirâmide. É portanto errado dizer que nossa sociedade se deforma, que se estende ou que, ao contrário, se homogeneiza. Antes de tudo, porque passamos de uma representação da sociedade enquanto sociedade de produção para uma sociedade enquanto mercado. Passamos da representação daquilo que se poderia chamar de um modo de produção para um modo de mudança (...) Em lugar da pirâmide, nossa sociedade apresenta a seguinte configuração. Há uma massa central, uma middle class, que corresponde a uma sociedade industrial e administrativa, secundária ou terciária, com operadores, funcionários públicos, executivos de alto escalão, empregados. É a massa majoritária das pessoas que têm um acesso considerado normal na ordem do consumo (equipamentos domésticos, automóvel etc.) e que dispõem também, mais ou menos nas mesmas condições, de uma segurança bastante forte, de um alto nível de proteção social. Dessa massa, distinguem-se as categorias que não são definidas por uma posição de classe, por um papel na produção, mas por uma posição no mercado (TOURAINE, 1992, p. 164-5, tradução nossa).

Desse modo, no raciocínio de Touraine, as questões essenciais das sociedades contemporâneas não estariam mais ligadas ao tema da exploração, mas sim ao da exclusão:

A vida das sociedades é principalmente constituída de alternâncias entre os problemas de conflitualidade interna e os problemas, ao contrário, de integração e exclusão. 0 problema hoje não é a exploração, mas a exclusão. Conseqüentemente, o problema concreto é criar os instrumentos e as formas de ação política que permitam uma integração social, antes que seja tarde demais e que entremos no modelo americano pelo seu pior lado, isto é, a segregação e a "guetização" (TOURAINE, 1991, p.13, tradução nossa).

Mas ao contrário do que afirma Touraine, o conceito de exclusão não invalida o conceito de exploração $0^{6}$. Pelo contrário, a compreensão daquele

\footnotetext{
${ }^{6}$ Utilizamos aqui o conceito de exploração num sentido largo, como em Casanova (2002), segundo o qual a exploração não diz respeito apenas à extração de mais-valia ocorrida sobre a classe trabalhadora na esfera da produção, mas também à má distribuição de riquezas, na esfera da
} 
beneficia-se deste. 0 processo de exclusão social que vimos descrito como ruptura de laços sociais realiza-se a partir de uma posição de classe determinada. Não são os donos dos meios de produção que sofrem processos de exclusão, mas os trabalhadores que se situam nos extratos mais baixos de sua classe. 0 processo de vulnerabilização e precarização pelo qual eles passam é um processo de intensificação da exploração de seu trabalho. Além disso, a lógica que governa esse processo é aquela da acumulação capitalista. Essencialmente, trata-se de luta de classes.

\section{CONSIDERAÇÕES FINAIS}

No âmbito da vida individual, o conceito de exclusão social como condição a que se chega pela ruptura de laços é uma hipótese distante das possibilidades reais. Afinal, a idéia de condição remete a um estado fixo de isolamento social, que na prática não é possível, já que mesmo que haja mecanismos excludentes, ainda assim existem necessariamente relações sociais para todos os que vivem em sociedade. Já quando pensado como processo, o conceito de exclusão social permite identificar mecanismos desencadeadores do isolamento e da precarização das condições de vida nas trajetórias individuais.

Já para pensar as relações na esfera macro-social, o conceito mostra-se pouco explicativo. Três fatores contribuem para isso.

Em primeiro lugar, a oposição da exclusão à integração social traz algumas armadilhas. Uma delas consiste em tratar a exclusão como algo atípico, em vez de parte e conseqüência essencial do modo de funcionamento das sociedades capitalistas. Além disso, a idéia da integração conduz à subestimação da contradição presente nas sociedades e dificulta que se enxergue confronto e superação. Uma das principais perdas promovidas por essa perspectiva está na idéia de que o conceito de exclusão substitui o de exploração nas últimas décadas. Contudo, como vimos, exclusão e exploração são duas facetas derivadas de um processo centrado na mesma lógica da acumulação de capital, com ampla influência de um sobre outro: a acentuação da exploração é o eixo de um processo excludente de precarização das condições de trabalho e de vida, e a exclusão de muitos é condição de acentuação e legitimação da exploração, como a situação possível e mais desejável frente a um cenário ainda pior. Além disso,

circulação, tanto intra como inter-nações. 
a exclusão opera sob e sobre determinadas relações de classe: a maior ou menor vulnerabilidade à exclusão depende da posição de classe, por sua vez alterada pela trajetória excludente.

Um segundo fator de perda de capacidade explicativa a respeito dos mecanismos geradores da exclusão social está no centramento da análise sobre os indivíduos. Ao se enfatizar a idéia de perda de vínculos de caráter individual, abre-se margem para a idéia de inadaptação pessoal. Por sua vez, a ênfase à atomização nubla a percepção do que há em comum entre os que vivenciam 0 processo de exclusão. Mesmo os exemplos de mobilização de grupos que poderiam ser classificados como "excluídos" - trabalhadores rurais sem-terra, sem-teto, desempregados etc. - perdem-se de vista quando se ressalta a idéia errônea de que os "excluídos" seriam necessariamente "não-forças" políticas e sociais.

Por fim, podemos dizer que sob a perspectiva dos laços sociais, a descrição da exclusão social é mais forte que a análise porque, ao se confundirem causas e características do fenômeno, não se chega a dissecar suas raízes. Vários estudos citam fatores gerais que estão na origem da exclusão (desemprego, crise dos sistemas de proteção do Estado, individualização crescente), mas não explicam como operam as relações sociais que os geram.

Portanto, o conceito de exclusão social pode servir como uma ferramenta inicial para uma análise no âmbito das trajetórias individuais, maséessencialmente descritivo e pouco analítico para pensar a sociedade em seu conjunto.

\section{REFERÊNCIAS}

BAREL, Yves. Le Grand Intégrateur. Connexions, Paris, n.56, pp.85-100, jan, 1990. BAUMAN, Zygmund. 0 mal estar da pós modernidade. Rio de Janeiro: Jorge Zahar Editores, 1998.

BUARQUE, Cristóvam. O que é apartação: o apartheid social no Brasil. São Paulo: Brasiliense, 1999.

CASANOVA, Pablo Gonzales. Exploração, colonialismo e luta pela democracia na América Latina. Petrópolis: Vozes, 2002.

CASTEL, Robert. Les metamorphoses de la question sociale: une chronique du salariat. Paris : Fayard, 1995. 
CLAVEL, Gilbert. La societé d'exclusion: comprendre pour em sortir. Paris/ Montréal: L'Harmattan, 1998.

ESCOREL, Sarah. Vidas ao léu: trajetórias de exclusão social. Rio de Janeiro: Fiocruz, 1999.

FERREOL, Gilles. Tranformations de l'institution familiale. In: FERREOL, Gilles. (éd.). Intégration \& exclusion dans la societé française contemporaine. Lille: Presses Universitaires de Lille, 1992.

GAULEJAC, Vincent \& TABOADA-LÉONETTI, Isabel. La lutte des places. Marseille/ Paris: Hommes et Perspectives/Desclée de Browuer, 1994.

KOWARICK, Lucio. Sobre a vulnerabilidade socioeconômica e civil: EUA, França e Brasil. Revista Brasileira de Ciências Sociais [on line]. São Paulo, n.51 (v.18), pp.61-86, ago, 2002.

MINAYO, Maria. O desafio do conbecimento: pesquisa qualitativa em saúde. São Paulo: Hucitec, 1993.

NASCIMENTO, Elimar Pinheiro. A exclusão social na França e no Brasil: situações (aparentemente) invertidas, resultados (quase) similares?. In: DINIZ, Eli; LOPES, José Sérgio Leite; PRANDI, Reginaldo. (orgs.). O Brasil no rastro da crise: partidos, sindicatos, movimentos sociais, Estado e cidadania no curso dos anos 90. São Paulo, Hucitec/Anpocs/Ipea, pp.289-303, $1994 a$.

Hipóteses sobre a nova exclusão social: dos excluídos necessários aos excluídos desnecessários. Cadernos CRH, Salvador, pp.29-47, jul.-dez, 1994 b.

OLIVEIRA, Luciano. Os excluídos "existem”? Notas sobre a elaboração de um novo conceito. Revista Brasileira de Ciências Sociais. São Paulo, n.33 (vol.12), pp.4951, fev, 1997.

PAUGAM, Serge. La disqualification sociale: essai sur la nouvelle pauvreté. Paris: Presses Universitaires de France, 1991.

POCHMANN. Marcio e AMORIM, Ricardo (orgs.). Atlas da exclusão social no Brasil. São Paulo: Cortez, 2003.

POCHMANN, Marcio. O emprego na globalização: a nova divisão internacional do trabalho e os caminhos que o Brasil escolheu. São Paulo: Boitempo, 2005.

ROCHA, Sonia. Pobreza no Brasil:o que mudou nos últimos 30 anos? In: VELLOSO, João Paulo dos Reis e ALBUQUERQUE, Roberto Cavalcanti de. (orgs.). Cinco décadas de questão social e os grandes desafios do crescimento sustentado. 
Rio de Janeiro: José Olympio, pp.179-219, 2005.

SILVER, Hilary. Exclusión social y solidaridad social: tres paradigmas. Revista Internacional del Trabajo, vol.113, n.5-6, pp.607-662, 1994.

TOURAINE, Alain. Face à l'exclusion. Esprit. Paris, n.169, pp.7-13, fev, 1991.

Inegalités de la societé industrielle, exclusion du marché (1992). In:

Affichard, Joëlle et Foucauld, Jean-Baptiste de (dirs.). Justice sociale et inegalités. Paris: Esprit, pp.163-174, 1992.

. Um novo paradigma: para compreender o mundo de hoje (2006). Rio de Janeiro: Vozes.

XIBERRAS, Martine. Les théories de l'exclusion: pour um construction de l'imaginaire de la déviance. Paris: Méridiens Klincksieck, 1994. 